In B. Pizziconi \& M. A. Locher (Eds.), Teaching and Learning (Im)politeness (pp. 185-209). Berlin and Boston: de Gruyter Mouton.

Miriam A. Locher

\title{
7 "After all, the last thing I wanted to be was rude": Raising of pragmatic awareness through reflective writing
}

\begin{abstract}
This study reports how pragmatic knowledge surfaces and is reflected in a corpus of reflective writing texts written by medical students at a British university in connection with a communication skills course $(\mathrm{N}=189)$. The questions pursued are 'which communication skills are taught?'; 'what communication skills surface in the students' texts?'; and 'what is the link to interpersonal pragmatics'? The methodology employed consists of critical close readings of the texts with an interpersonal pragmatics lens within the framework of relational work. The study reveals that the students choose to write about interpersonal (e.g. empathy, rapport) and transactional (e.g. how to formulate questions) communication skills and they identify relational issues that overlap to a striking degree with issues that are currently debated in (im)politeness research: the importance/value of rapport and empathy; the presentation of self and the interpersonal consequences of communication on relationships; the challenge of finding the right level of relational work; and the role of emotions. The chapter ends with a discussion of the potential of the reflective writing task for awareness raising of pragmatic rules in teaching about (im)politeness.
\end{abstract}

Keywords: reflective writing, socialization, relational work, metapragmatic comments, empathy, rapport

\section{Introduction}

"After all, the last thing I wanted to be was rude" is a comment written by an English medical student on his communication skills in a reflective writing task. It expresses a concern about how he did not want to come across in the (novice) doctor-patient interaction that he describes and zooms in on interpersonal issues. This metapragmatic comment on (in)appropriate behaviour and many others of its kind are the impetus for us ${ }^{1}$ to explore with an interpersonal

1 I use the first person plural pronouns when referring to the author of this paper because, while this is a single-auhored work, the insights I present here build on many research steps that were taken jointly by the team working on the Swiss National Science Foundation project 'Life (beyond) Writing': Illness Narratives (2009-2012). See acknowledgments. 
pragmatics lens the corpus of 189 reflective writing texts by medical students from an English university that constitutes the data for this study. During their training, the students take a compulsory course on clinical communication skills where they learn the importance of taking medical histories, listening to patients, using open and closed questions, keeping eye contact, showing adequate empathy and creating rapport and trust among other skills. The students were asked to submit a written text of two to three pages in which they should first recall a memorable encounter with a patient, then reflect on their communication skills during that episode and finally conclude by formulating aims for future conduct (cf. Branch and Paranjape 2002; Hampton 2010a, 2010b on reflective writing). While the teaching of the clinical communication skills does not explicitly include raising awareness of politeness issues on a theoretical level as discussed in linguistics, the students nevertheless themselves raise concerns about relational and interpersonal issues in their reflections, which are of interest to (im)politeness scholars. What we witness, then, is that the students become aware of recognizing and developing their own Community of Practice norms (Wenger 1998; Eckert and McConell-Ginet 1992) with respect to relational work. In this chapter, I thus do not explore how students learn how to express themselves politely in a second language, but rather focus on how young professionals gain knowledge of pragmatics that they acquire with a fairly straightforward teaching method, and how the students themselves link their insights to (im)politeness concerns.

The chapter first positions the study theoretically (section 2) and then moves to a more detailed description of the data (section 3). Section 4 deals with establishing further what the students have been taught concerning communication skills (section 4.1), what communication skills they choose to discuss in their texts (section 4.2) and how these discussions are linked to relational work and interpersonal pragmatics (section 4.3). The chapter concludes with observations on reflective writing as a tool to raise awareness of pragmatic issues and skills.

\section{Theoretical background and positioning of the study}

This study explores the reflective writing texts against the background of the acquisition of pragmatic knowledge. Robin Lakoff (1973: 296), as the earliest linguist to specifically put politeness on the research agenda, stated quite clearly that "[j] ust as we invoke syntactic rules to determine whether a sentence is to be considered syntactically well- or ill-formed, and in what way it is ill-formed if it 
is, and to what extent, so we should like to have some kind of pragmatic rules, dictating whether an utterance is pragmatically well-formed or not, and the extent to which it deviates if it does.” This led her to combine Grice's (1975) Cooperative Principle with a Politeness Principle. In the same vein, Brown and Levinson ([1978] 1987) and Leech (1983) later also build on the Cooperative Principle (see Kádár and Haugh 2013; Locher 2012, 2013 for recent overviews of the history of politeness research). Important for my observations here is the fact these theories point out that pragmatic knowledge is closely tied to context. Scholars have also pointed out that we are not born with pragmatic competence; instead people need to learn it in socialization processes (see, e.g., Ochs 1988, 1999; Rose 2000: 28-29). This assumption can easily be brought in line with Scollon and Scollon's (1990, 2001) work on what they term the 'discourse system,' with the idea of communities of practice (Wenger 1998; Eckert and McConell-Ginet 1992), and with work on identity construction (Bucholtz and Hall 2005), as I will explain in what follows.

Scollon and Scollon (1990), like Lakoff (1973) above, argue that people acquire rules of conduct through socialization that are often subconscious. This is analogous to the acquisition of grammar rules in one's first language that can also often not be phrased on a meta-level by all native speakers alike. Importantly, Scollon and Scollon (1990: 285) highlight that these rules are deeply ingrained and closely tied to a person's understanding of self. This observation has also been made with respect to the notion of frames (Tannen 1993) or activity types (Levinson 1992), the knowledge of which is entailed in a discourse system: in socialization processes people learn about ways of behaving and from these past experiences they develop expectations about action sequences and rights and obligations of conversational partners. Typically, people become more aware of these expectations about appropriate behaviour in intercultural communication situations or in situations of conflict where people are at crosspurposes. Such awareness may also surface in situations where people are specifically asked to reflect on communication, as is the case in the data for this study.

Scollon and Scollon (1990: 261) identify a number of discourse areas in which different patterns for different groups of people can be observed: "the presentation of self, the distribution of talk, information structure, and content organization.” They then report how Athabaskan-English speakers (i.e. speakers who have been socialized as Athabaskans) and speakers of English socialized in the "dominant, mainstream American and Canadian English-speaking population" (Scollon and Scollon 1990: 261) potentially misunderstand each other on an interpersonal level because they adhere to different discourse systems (both parties striving to maintain and adhere to their own discourse systems) despite 
the fact that both speak English. For example, they mention that there are different tolerance thresholds between the two groups for pauses, for self-praise, or for making predictions. The argument is that both groups have developed expectations about how to behave and they notice when their conversational partners do not follow the same norms. Without a conscious awareness that there are equally valid discourse systems among different people, this might lead to negative assessments of the conversational partners and to stereotyping (see also the work by Gumperz and Roberts 1978, on 'developing awareness skills for interethnic communication'). In fact, in the approach to (im)politeness studies proposed by Locher and Watts $(2005,2008)$, these judgments are a key element of the proposed theoretical framework. It is argued that judging others about their use of relational work results in assessments of people being rude, impolite, uncouth, polished, polite, etc. These assessments are linked to judgments about the person as such so that we can detect a close link to identity construction (Locher 2008, 2012; Spencer-Oatey 2007; see also the insights gained in anthropological linguistics on the link between metapragmatic comments and personhood, Agha 2007; Lo and Howard 2009).

Scollon and Scollon (1990: 285) argue that, because the discourse system is closely tied to a person's understanding of self, people cannot easily shed expectations about how interaction should ensue when they are engaged in different practices. This retaining of expectations on behavioural and linguistic patterns is a phenomenon that has also been described in terms of pragmalinguistic transfer and socio-pragmatic failure (e.g. Béal 1994). García-Pastor (2012) reports that

\footnotetext{
Pragmatics in language learning has typically been conceived as pragmalinguistics and sociopragmatics. Pragmalinguistics has been identified with a set of linguistic resources [e.g. indirectness, routines, hedges] for conveying illocutionary and interpersonal meanings (Leech 1983; Thomas 1983). In turn, sociopragmatics has been equated with the socio-cultural factors underlying the use of these resources across contexts (ibid.). (García-Pastor 2012: 13, italics in original)
}

So, when L2 learners transfer pragmatic strategies from their L1 into their L2 usage, they have not yet acquired the understanding that the pragmatic strategies differ (let alone having acquired the knowledge of L2 pragmatic strategies). Misunderstandings are likely when the different discourse systems differ (e.g. giving different importance and weight to different types of face-threatening acts, or assessing distance and closeness differently; Béal 1994).

However, we do not even have to move to intercultural situations in order to find clashes of discourse systems. One can also make a case for arguing that 
different communities of practice ${ }^{2}$ may develop different norms and expectations about roles and adequate behaviour. These differences might be barely perceptible or rather large (see, e.g., Culpeper 2008: 30, on different types of norms). Making the link to the data studied here, one could state that becoming a professional health practitioner in Britain also entails learning how to comport oneself in a particular way in the British health system and this suggests that the struggle experienced by the medical students in this study has to do with their negotiating different identities as students and novice doctors (see Gygax, Koenig, and Locher 2012).

One means employed in medical education to raise awareness and understanding of how a practice works is 'reflective writing.' This type of writing involves "consideration of the larger context, the meaning, and the implications of an experience or action" (Branch and Paranjape 2002: 1185). Typically, the texts are structured into three steps: description, interpretation (or reflection) and outcome (or conclusion) (Hampton 2010a, 2010b; for an extended version, see Watton, Collings and Moon 2001). While reflective writing is often used during the education phase in medical schools (and elsewhere), it is recommended as a life-long tool for professionals of any kind to keep learning from their experience (Brady, Corbie-Smith and Branch 2002; Mann, Gordon and MacLeod 2009; Monash University 2012; Shapiro, Kasman and Shafer 2006). Watton, Collings and Moon (2001) quote Gibbs (1988) on the importance of reflection:

It is not sufficient simply to have an experience in order to learn. Without reflecting upon this experience it may quickly be forgotten, or its learning potential lost. It is from the feelings and thoughts emerging from this reflection that generalisations or concepts can be generated. And it is generalisations that allow new situation to be tackled effectively. (Gibbs 1988: 9)

As a practice which can serve to reveal insights on all levels of interaction, reflective writing has the potential to raise practitioners' awareness of relational issues. In what follows I study such reflective writing texts from an interpersonal pragmatics perspective. ${ }^{3}$ This means that I assume that the texts will show

2 Scollon, Scollon and Jones (2012: 9) argue that the concept of 'communities of practice' refers "to bounded groups of people (defined respectively by the texts they use and by the practices they engage in together), whereas discourse systems refer to broader systems of communication in which members of communities participate."

3 The label 'Interpersonal Pragmatics' is not meant to designate a new theory or a fixed set of methodologies but refers to a perspective (Locher and Graham 2010: 2). We propose to use it for the interdisciplinary field that gives the relational/interpersonal centre stage in its research endeavours; studies in interpersonal pragmatics "explore facets of interaction between social actors that rely upon (and in turn influence) the dynamics of relationships between people and how those relationships are reflected in the language choices that they make" (Locher and Graham 2010: 2; see also Haugh, Kádár and Mills 2013: 9). 
evidence of relational work, i.e. "all aspects of the work invested by individuals in the construction, maintenance, reproduction and transformation of interpersonal relationships among those engaged in social practice" (Locher and Watts 2008: 96), which is part of pragmatic competence, and closely tied to the presentation of self (see Bucholtz and Hall 2005; Locher 2008, 2012; SpencerOatey 2007). Without denying the importance of reflections on the numerous topics raised and the transactional patterns discussed by the students, the focus on interpersonal issues allows me to isolate metapragmatic comments on relational work and to observe what kind of issues the students raise.

\section{Data}

The data for this study was collected for an interdisciplinary project entitled 'Life (beyond) Writing': Illness Narratives (funded by the Swiss National Science Foundation 2009-2013), which involves literary studies, linguistics and transfer to teaching in the medical humanities (see Gygax et al. 2013). In this chapter we report on the linguistics side of the project and in particular on a corpus of 189 texts of one to four pages in length (i.e texts of around 1,300 words on average, for a total of 249,708 words). These texts were composed by medical students from the University of Nottingham in 2010 and 2011 in connection with a clinical communication skills course run by Victoria Tischler (see also Oyebode and Tischler 2015). The texts were collected by Tischler for the project but the task was optional for the students. ${ }^{4}$ The students were assured anonymity and gave consent to being part of the study. They also provided background information about themselves: The students were between 19 to 22 years old, 63 per cent were female and 88 per cent indicated English as their first language. Languages in addition to English were often indicated, but no single language group was larger than eight people ( 4 per cent). ${ }^{5}$ Eighty-four per cent reported having grown up in the UK, so that the vast majority of the students in this study were familiar with British interactional norms. The texts are written in English.

The students were in their second year of a five-year medical training degree at the time of writing. They gained experience with clinical interaction during regular hospital and general practice visits. In addition, they had completed a

4 In addition the students had to write a narrative text in which they were encouraged to be creative as a compulsory part of the course for Tischler. These texts are not part of the study reported in this chapter (see Oyebode and Tischler 2015).

5 Fifty-four people (29\%) indicated more than one language. The languages most mentioned were: Malay (8), Thai (7), Gujarati (5), Urdu (5), Arabic (4), Cantonese (4), Hindu (4), Punjabi (4) and Tamil (4). In addition to these, 18 more languages were indicated. 
clinical communication skills module in the first year of the course, which introduced them to a number of topics about challenging communication situations in the British health system (see next section).

As explained in the previous section, engaging in reflective writing is an established professional practice. The wording and design of the task was adopted from a course at the University of Basel, where Alexander Kiss, who is a research team member, was instrumental in implementing reflective writing as a compulsory part of the education of medical students. The didactic aim of the task is to introduce students to this means of learning for the first time (in the hope that they will adopt it throughout their career) and to embed this introduction within a course on clinical communication skills in order to improve awareness of such skills and health communication in general. The students received in-class explanations on the task and detailed written instructions on how to compose their text. These instructions suggest following the classic three parts of reflective writing (description, reflection, conclusion) and can be summarized as follows (see also Locher, Koenig, and Meier 2015):

- The students write about a conversation/encounter with a patient that impressed them most during their attachment at a GP surgery or clinical surgery.

- They are invited to introduce/describe the situation and the characters of the chosen episode and to represent direct speech in the form of drama dialogue for key passages.

- They are asked to reflect on their communication skills, on their emotional reactions and to draw conclusions about future behaviour.

The detailed instructions also particularly invite the students to focus on communication skills and to include reflections on the feelings and emotions that were part of the experience. Since these triggers are particularly important for this chapter, the relevant sections are quoted here in full (the asterisk * identifies compulsory parts that must be addressed):

\section{Situation}

* Describe the patient (age, relevant diagnosis, first impression - appearance, posture, language, anything else noticeable, etc.)

* What was the reason for the encounter?

* Describe what you talked about by using verbatim speech (the exact words) as much as possible. If you cannot remember the exact wording, reconstruct the dialogue for the crucial moments as well as possible.

1. Describe how you felt after the encounter.

2. Try to describe how the patient might have felt after the encounter. 


\section{Reflections on communication with a patient}

* [1. The uniqueness of the encounter...]

* 2. Communicative aspects

a) Did I communicate with the patient as I intended to?

b) Did the conversation proceed as planned?

c) If yes, why and in what ways have I achieved this?

d) If no, what went wrong and what could I have done differently?

\section{Aims}

* What have I learnt from this encounter?

* What would have helped me to manage/shape the encounter in a better way?

* What aspects of my behaviour and language will I change in order to improve my next encounter with a patient with a similar problem?

The texts in this corpus can be studied from many different angles. So far we have explored the importance of emotions in the described interactions (Locher and Koenig 2014), the emergence of linguistic identity construction (Gygax, Koenig and Locher 2012), and the role of narrative elements within the text composition (Locher, Koenig, and Meier 2015). In this chapter, I turn to metapragmatic comments on relational work against the backdrop of what the students have been taught concerning clinical communication skills and what they choose to write about.

\section{The surfacing of relational work in reflective writing: Analysis}

As the medical students were asked to specifically reflect on their communication skills and how they felt during or after the interaction (see section 3), this data lends itself to a study of metapragmatic comments on relational work. The methodology employed consists of close readings of the texts with an interpersonal pragmatics lens (cf. Locher and Graham 2010) within the framework of relational work (cf. Locher and Watts 2005, 2008; Locher 2012). We first discuss which communication skills are taught as input during the communication skills course in order to establish the backdrop for the second step in which we establish which communication skills surface in the texts. Finally, we will turn to the interpersonal pragmatics themes that we can detect in the compositions. 


\subsection{Teaching input on clinical communication skills}

The medical students wrote their texts in connection with the clinical communication skills module that they took in their second year of a five year medical degree. In this second module, the students were introduced to more challenging forms of clinical communication (communication with patients with mental health problems, learning difficulties or hearing impairment, and explaining medical information to lay people). In the previous year they had completed a clinical communication skills module during which they were exposed to topics such as how to structure a clinical interview, to use different question types, to signal empathy, to build rapport, to use non-verbal communication, and they received input on the roles of doctor and patient. During this first year module, they also received input on the importance of reflective writing and they learnt how to identify types of communication skills from a transcript and to reflect on communication skills. In addition to input from these courses, the students also gained hands-on experience of clinical interaction through attachment to a GP and regular hospital visits. Next to course internal requirements that the students have to fulfil, they also need to pass an Objective Structured Clinical Examination (OSCE), in which students demonstrate communication skills whilst being assessed by an examiner.

In discussion with Tischler, the clinical communication skills listed in Table 1 were identified as being part of the core teaching aims for the medical students in this module (see also Maguire and Pitceathly 2002). ${ }^{6}$ For this study, they have been organized into groups that differ in their general pragmatic orientation. Group (1) deals with a general stance that the students should be able to adopt flexibly. The skills in group (2) focus on transactional skills such as delivering information, structuring the consultation, listening, mirroring and summarising the patient's positions (in order to trigger confirmation or further information). The skills in group (3) highlight relational and interpersonal issues such as creating rapport and building trust, or showing empathy and sympathy. Finally, group (4) lists non-verbal skills that are also taught as being important for successful doctor-patient interaction and which can serve both interpersonal and transactional purposes.

6 Some of these clinical communication skills may well be culture-dependent. For example, with respect to keeping eye contact that the students often mention in their texts, Pizziconi (2009: 232) reports an episode where a Japanese nurse avoided maintaining eye contact with her patient, which appears to have been a respectful way of comportment. Awareness raising of cultural differences is, however, not part of the teaching aims of this module. 
Table 1: Clinical communications skills taught at Nottingham

\begin{tabular}{lc}
\hline (1) General skills & (3) Interpersonal skills \\
- adapt/be flexible & - create rapport/build trust \\
& - empathize \\
& - sympathize \\
& - reassure and reinforce \\
& - involve the patient \\
& - use (social) chit chat \\
& (4) Non-verbal skills \\
(2) Transactional skills & - use non-lexical utterances \\
- deliver information/explain & - use body language/tone of voice \\
- structure/signpost & - respond to verbal and non-verbal cues \\
- use questions & - spatial arrangement (e.g. moving chairs \\
- listen & so that there are no barriers) \\
- mirror & \\
- summarize & \\
- give patient time/conversational space & \\
\hline
\end{tabular}

The skills listed in all four groups serve as an orientation for the next step in the analysis when we are looking for what communication skills the students choose to write about in their reflective writing texts.

\subsection{The communication skills chosen for reflection}

In order to understand the importance of the discussion of communication skills within the composition of the texts, the research team established what the main themes of the student texts were by answering the question 'what is this text about?'. The coders (Regula Koenig and three student interns) could choose between one to three themes per text from a previously established set of finegrained topics. ${ }^{7}$ Since a text could raise many issues in passing and the question was about the 'main themes' raised, the team decided to reach a consensus about one to three important themes per text by discussion rather than independent coding (see, MacQueen et al. 2008; Namey et al. 2008). Table 2 shows the

7 The topics were developed bottom-up and went through several testing periods until the team of coders (Regula Koenig as a core team member plus two to three interns) reached a coder agreement above 75 per cent for the main topic categories. The difference between the term topic and theme as we use it in this study is purely instrumental. Theme refers to the main point of the texts, while topic is any mention of a particular issue, even if it was just done in passing. There were 29 themes to choose from (while the topic categories were much more fine-grained containing many sub-categories, leading to a total of 92 topics). 
main theme choices for the entire 189 texts comprised in the Nottingham reflective writing corpus. Not surprisingly, communication skills ranked highly, since the task description clearly asked the students to write about them. In 135 of 189 texts (71\%) communication skills were one of the main concerns of the texts. The other categories were less prominent and chosen in below 23 per cent of the texts. It is noteworthy that the emotions of the patient (in 23 per cent of the texts) and the emotions of the student (in 17 per cent of the texts), which arguably constitute a topic that has to do with interpersonal issues rather than transactional or general issues, appears among the top themes the students choose to write about. This is a finding I will return to below.

Table 2: Thematic analysis of the Nottingham corpus (only categories of more than $10 \%$ are displayed)

\begin{tabular}{lrr}
\hline & In \# of texts & \% of $\mathbf{~ = ~} \mathbf{1 8 9}$ \\
\hline Communication skills explicitly discussed & 135 & 71 \\
Emotions patient & 43 & 23 \\
Other & 41 & 22 \\
Emotions student & 33 & 17 \\
Special medical conditions & 33 & 17 \\
Impact of illness on patient's life & 29 & 15 \\
Setting (e.g. several participants/people, home visit) & 26 & 14 \\
\hline
\end{tabular}

Since the overall topic orientation of the texts is not the focus of this chapter, we will directly move on to a discussion of the communication skills mentioned. All 189 texts were tagged with respect to 16 communication skills listed in section 4.1. The categories 'reassurance and reinforcement' and 'spatial arrangement' did not occur, while 'sympathy' was mentioned numerous times but was not systematically differentiated from empathy in the coding process (mainly because the students did not separate the two concepts consistently). 'Responding to verbal and non-verbal cues' was subsumed under the other non-verbal categories. We added the category 'be patient' (group 2) bottom-up since the students raised this transactional skill as pertinent to the communication process. We also allowed the open category 'other' for issues that did not match any of the taught skills or that did not warrant to be turned into a bottom-up category of its own.

Example (1) serves as an illustration to show how students reflect on their communication skills and displays the categories in diamond brackets (all examples are quoted verbatim; no corrections have been made to the texts apart from bold highlighting). 
(1) I feel I communicated well with Mr X and I feel the conversation proceeded as planned. As I mentioned earlier, depression is a unique condtion and can very easily give individuals a sense of helplessness. Routine tasks become intolerable as concentration fades and unhappy thoughts intrude on our lives. I sensitvely listened <listen> to $\mathrm{Mr} \mathrm{X}$, recognised his sadness and attempted to show empathy <empathy> towards him by leaning forward <use of body language $>$ whilst talking to him and by maintaining eye contact $<$ use of body language $>$ thoughout the encounter. I also used empathetic language <empathy> such as - "That must have been dificult for you." to make Mr X feel that I was listening to what he had to say. After the encounter I realised that patients are invividuals with individual needs and emotional responses. What maybe be normal for someone may be the opposite for somone else. Therefore it is important to be prepared and spend time over a consultation especially with patients as vulnerable as $\mathrm{Mr} \mathrm{X}$, to gain all the important signs and symptoms. (N-006, highlighting and tagging added)

The passage is taken from the reflection part where the student discusses how she communicated with a person who suffers from depression. The lexemes highlighted in bold were assigned to one of the clinical communication skills introduced above. While the text clearly enlists the skills taught, the student stresses what she has learnt.

Our quantitative analysis recorded the presence or absence of mention of clinical communication skills in each text but did not tally how often a skill was mentioned per text. Firstly, we find that the students usually reflect on more than one communication skill in their texts: 88 per cent of the texts reflect on 2 to 7 , while 44 per cent alone reflect on either 4 or 5 skills. This in itself means that the students are aware of the complexity of their interactional encounters.

Secondly, turning to the type of communication skills mentioned, we see in Table 3 that among the many options that the students can choose to write about, they particularly focus on empathy and rapport/building of trust from the interpersonal skills and the use of questions and structuring/signposting in the case of transactional skills. Furthermore, the use of body language and tone of voice (serving both interpersonal and transactional purposes) occurs as often as the mention of the two interpersonal skills. Looking at the distribution, empathy and rapport/building trust and use of body language/tone of voice are mentioned in 60 per cent of all the texts; in the case of using questions and structuring/signposting this is the case in 54 per cent. This quantitative result 
gives us an impression of the importance that the students give to both interpersonal and transactional communication skills. That the two top ranking skills are from the interpersonal group warrants looking more closely at evidence of relational work in the corpus.

Table 3: Occurrence of mention of communication skills in the Nottingham corpus, ordered according to frequency of occurrence

\begin{tabular}{llrr}
\hline Type & Communication skills & Total & \% in 189 texts \\
\hline Interpersonal & empathize & 115 & 60.85 \\
Interpersonal & create rapport/build trust & 114 & 60.32 \\
Non-verbal & use body language/tone of voice & 112 & 59.26 \\
Transactional & use questions & 103 & 54.5 \\
Transactional & structure/signpost & 103 & 54.5 \\
& other & 97 & 51.32 \\
Transactional & (active) listening & 44 & 23.28 \\
General & adapt/be flexible & 36 & 19.05 \\
Non-verbal & use non-lexical utterances & 23 & 12.17 \\
Non-verbal & be patient & 19 & 10.05 \\
Transactional & deliver information/explain & 16 & 8.47 \\
Interpersonal & involve the patient & 8 & 4.23 \\
Interpersonal & use (social) chit chat & 8 & 4.23 \\
Transactional & give patient time/conversational space & 5 & 2.65 \\
Transactional & summarize & 4 & 2.12 \\
Transactional & mirror & 3 & 1.59 \\
\hline & & &
\end{tabular}

\subsection{Evidence of awareness of interpersonal concerns and (im)politeness}

Using the quantitative analysis to obtain a first impression about the importance of interpersonal issues, we then turned to a close reading of the first 50 texts in the corpus. One of our student interns (Andrea Wüst) and myself read the texts and highlighted passages in which relational issues were discussed. From these passages we then developed a number of recurrent themes, which illustrate what the students report as having learnt with respect to relational issues. This analysis has not been quantified and, at this stage, serves the function of theme identification. From this qualitative close reading of 50 texts, three major issues emerge: (1) The importance/value of rapport and empathy; (2) The presentation of self; (3) The role of emotions. In many cases the students did not discuss these issues in isolation but in combination. This will also be visible in the examples chosen for illustration. ${ }^{8}$

8 In some instances, we draw on examples taken from texts beyond the first 50 in the corpus, when a point can be particularly well illustrated. 
The first theme deals with reporting on awareness raising about the value of empathy and rapport. In clinical communication, signalling empathy (rather than just feeling it) is portrayed as a tool for enhancing rapport and therefore relationship building with patients, and clinicians are advised to develop ways of showing empathy for its therapeutic benefits such as encouraging disclosure and reducing anxiety, its positive impact on adherence to treatment, but also because "patients' emotional needs" should be seen as a "core aspect of illness and care” (Halpern 2003: 673). Example (2) is taken from a text in which the student gives the following reason for choosing the described encounter: "I remember this encounter because of the way the patient came into the surgery room looking perfectly fine with no outward signs of illness and then proceeded to break down in front of me as she explained how long she had been feeling under the weather" (N-019). He then explains how he was asked to see the patient on his own in order to take her history and report it to the GP. He starts his reflection part in the following way:

(2) The thing I think is unusual about this interview is how empathy is such a powerful tool at both eliciting a person's true emotions and establishing a rapport with them. [...] I also think my facial expression played a major role in how the conversation proceeded as when I mirrored the patient her true feeling came out. Also when I reassured the patient, I smiled which in turn made her smile and feel more secure in the fact people cared. [...] I also used empathy to great effect, I think my facial expressions and eye contact were key in this. (N-019)

The passage shows that this student does not simply report that he established rapport and signalled empathy, but there is also an attempt at explaining how this was achieved (facial expression, smiling, eye contact). ${ }^{9}$ (This is in contrast to quite a number of students who did not go beyond the mentioning of key concepts.) Crucially, however, the student also evaluates the strategies and informs the reader that empathy is a "powerful tool at both eliciting a person's true emotions and establishing a rapport with them."

9 It is not discernable whether empathy is a genuine feeling in this example. In their text on vital clinical communication skills, Maguire and Pitceathly (2002: 698) introduce empathy under the label of being supportive: "Use empathy to show that you have some sense of how the patient is feeling ('the experiences you describe during your mother's illness sound devastating'). Use educated guesses too. Feed back to patients your intuitions about how they are feeling ('you say you are coping well, but I get the impression you are struggling with this treatment'). Even if the guess is incorrect it shows patients that you are trying to further your understanding of their problem." This discussion leaves open the possibility that the practitioner does not actually feel for the patient. 
This same learning experience is also reported by the student who composed N-056, in which she describes a history taking experience with a "72 year old caucasian female," who was particularly mistrustful of doctors.

(3) I was quite shocked and concerned as to the lack of trust that the patient had in doctors after the remarks that the patient kept making and the feelings that she was expressing. However, although the patient seemed to dislike doctors on the whole, she seemed to be very friendly towards me and another colleague who also took the patient's history after me. It seemed that she was very pleased by the fact that we came across to her a lot more friendlier and caring as she kept remarking that we were 'very nice girls' and said 'I don't mind talking to you'. Although I previously knew that establishing rapport with a patient was one of the most important things that a doctor should do when taking a history and talking to a patient, I do not think that until this encounter with this patient, I realised quite how important it was. I also did not realise how much impact the way in which a doctor comes across to a patient impacts on the way they think about other doctors on the whole, and how trusting or untrusting of other doctors they may become. It was also scary to think how much this trust would impact upon a patient's treatment and how they respond in terms of compliance to a doctor's advice. It is worrying to think that this patient may refuse to have essential vaccinations such as the flu vaccine, especially due to her old age, in the future due to these past encounters with doctors, whose intentions she probably just misunderstood. (N-056, emphasis added)

In (3), we see that the student grasps the importance of rapport not only because she went through the experience at the time, but, and this is the didactic purpose of reflective writing, this knowledge is made conscious by reflecting and reporting on it. This reporting on understanding why rapport matters goes beyond knowledge reported from textbooks and was a recurring theme in this and other texts. It is further illustrated by a number of students who explicitly make a link between creating rapport and patient compliance, and thus adhere to a rational means-end assessment of rapport as an interpersonal clinical communication skill:

(4) From my past experience I have found patient's can be quite guarded of the information I want, and only after I had developed a sufficient rapport with them were they willing to divulge this information. [...] From this encounter I have learnt the importance of keeping a conversation flowing to aid the development of rapport with the patient and therefore to elicit the information I needed from him. (N-021) 
(5) Therefore in future even though doctors have limited time to spend with each patient in a consultation, I will aim to develop a good rapport with patients since this will both make it easier to take a history and increase the likelihood of adherence in patients because the patient will want to discuss their problem with me and allow plenty of time for them to ask questions. (N-045)

(6) This encounter was very memorable because I built a genuine relationship with the patient. I have learnt that building a good rapport with a patient can greatly improve the detail and accuracy of the information elicited from an interview. (N-029)

In examples (4) to (6), the students report that building rapport or building a "genuine relationship" ultimately allows them as doctors to pursue their objective as information gatherers better - information which they need to form their diagnosis and to pursue with treatment. While these students seem to imply that information gathering is the main purposes of history taking (and some doctors would probably agree, but see Halpern 2006 above), they report on their insights that an interpersonal communication strategy facilitates their task.

Example (3) above also serves to illustrate the second main interpersonal issue: the presentation of self (see Scollon and Scollon 1990), which is connected to interpersonal consequences of communication on relationships and the challenge of finding the right level of relational work (see section 2 for pointers on linguistic identity construction and relational work). The author of N-056 writes that "I also did not realise how much impact the way in which a doctor comes across to a patient impacts on the way they think about other doctors on the whole, and how trusting or untrusting of other doctors they may become" (directly after the highlighting). What she stresses here is that she became aware that how one speaks and behaves has an impact on how one is seen and, in addition, that people assign values on how one speaks and behaves to an entire occupational group (this process may easily result in stereotyping; see Pizziconi 2009). This awareness can go in both directions: the student's own behaviour as a future doctor has an impact on how doctors will be seen and the student is judged in light of how doctors were perceived in the past. Interestingly, the student writes that the patient is quite happy to talk to her and implies that this was because she and her colleague were still considered to be "very nice girls" rather than mistrusted doctors. As discussed above, the student makes a direct link between creating rapport and patient compliance and thus also gives a rational rather than emotional reason for creating rapport. All in all, example 
(3) nicely illustrates that the student becomes aware of issues around the presentation of self, membership categorization, and the dynamics of identity construction in this new community of practice into which she is being socialized. This leads her to the realization that finding the right level of relational work is an achievement and has consequences for future interactions.

Worrying about the presentation of self and establishing a professional identity is a recurring theme in the corpus and is often accompanied by explicit metapragmatic comments on relational work, including comments about (im) politeness. Examples (7) to (10) illustrate some of these instances.

(7) Certain aspects of my own non-verbal communication could also have been changed to build rapport and come across as a open figure - examples include, smiling, looking interested and nodding. (N-012)

(8) In Part 3, I laughed politely when she said that she has Indian blood in her. I did that just to maintain the rapport between us. She did not mind me doing that but maybe some other patients would. [...] I will try to keep it to a nice polite smile next time just to avoid patient feeling that I was laughing at them. (N-005)

(9) I will also try and adapt my language to mirror words used by the patient to build rapport and help keep us on the same level. I must find the balance between empathetic and patronising responses for example by refraining from phrases like "poor you" when the patient describes something negative and use something like "That must have been hard for you." This will show empathy yet not demean the patient. (N-008)

(10) I have learnt how difficult and how emotionally demanding some consultations can be. I wasn't aware of how much of an effect the patient's upset would have on me; in the future I will try to remain empathic but I must also be aware of maintaining a professional amount of distance. (N-85)

In (7) the author of N-012 reports that he will strive to create an "open figure" in the future. The author of N-005 uses meta-language about relational work ("laughed politely," "a nice polite smile") to describe her past and future behaviour in an endeavour to make sure that the patient might not feel she is being made fun of through potentially inappropriate laughter. This shows that she is aware of the risk of being misunderstood when striving to "maintain rapport." A similar awareness is demonstrated in (9), where the student explains that the same sign can be interpreted as empathic or patronizing, so that how she behaves can result in positive or negative evaluations. In (10) the student 
contrasts showing empathy with maintaining professional distance, which reveals the underlying ideology that maintaining distance, rather than showing empathy, is a key element of a professional stance (see Locher and Koenig 2014, for a discussion of this text). The students in examples (7) to (10) thus also report on how they realize that their comportment has consequences for their presentation of self and that finding an adequate way of expressing oneself is challenging.

The third theme identified in the 50 texts is the role of emotions. While it was to be expected that the students would reflect on emotions since the instructions explicitly asked them to report on their feelings, it is nevertheless noteworthy that the students often choose 'memorable encounters' that specifically deal with their own and the patients' emotions (see section 4.2) and that they recurrently report on emotions in connection with interpersonal issues. For example, in (10) above, the student reports on an encounter with a patient whose emotional reaction affected the student to the point that she became emotional as well and struggled between showing empathy and keeping distance. ${ }^{10}$ There are many other examples in which the students discuss their feelings of unease and distress, or their worrying about not behaving appropriately, as exemplified in (11) to (13).

(11) I felt like I was explaining something to a child, although it was effective, I was scared he might feel patronized and so it was a challenge for me to perceive whether or not he felt this way. In the end I realized he had taken no offence in the way I explained it. (N-022)

(12) This was slightly frustrating as I didn't feel I was being rude or was acting in any way that would make the patient act so defensively and distant. (N-009)

(13) The first thing that struck me was that the patient sort of mumbled when speaking due to his illness. This made the encounter tricky, but also rather awkward for me as I wasn't sure whether to keep asking him to repeat things or just nod in a clueless manner. After all, the last thing I wanted to be was rude, and unfortunately this played on my mind throughout the interview. (N-144)

10 Also in example (3) above, the reported insights on the value of rapport and empathy is embedded within a discussion of how "shocked" and "concerned" the student was about the lack of trust in doctors that the patient displayed. 
What we see in examples (11) to (13) is that the students report negative feelings ${ }^{11}$ (being scared, frustrated, insecure) and link this to projected assessments of their behaviour by the patient. In other words, they assume that their comportment will be judged by the patient and that their particular behaviour might be assessed negatively as patronizing or rude. This connection between emotions and the act of judging one's own and other people's relational work has been argued to be a crucial element in interpersonal pragmatics, since emotions are key in arriving at an assessment (Culpeper 2011; Locher and Langlotz 2008; Langlotz and Locher 2012, 2013; Locher and Koenig 2014; Spencer-Oatey 2007, 2011). The examples also give further evidence of the link between the presentation of self and metapragmatic comments on relational work and nicely illustrate how the interactants take their own and the addressees' perspectives into account.

While 'politeness' or 'rudeness' are not explicitly mentioned in teaching, the students bring up these concepts in connection with the mention of emotions and identity construction in the form of metapragmatic comments. A lexical search in the entire corpus shows 29 occurrences of 'patronizing' where the students report wanting to avoid appearing in this manner; rudeness $(n=19)$ is mainly mentioned with respect to self, i.e. wishing to avoid to appear so, rather than talking about rude patients; mention of polite behaviour occurs in 17 cases; and impoliteness is not mentioned at all. Culpeper (2011) made similar observations about the prevalence of patronizing and rude as first order lexemes in his collection of reports on incidences that caused offence. What the discussions of the examples in this section shows is how intricately intertwined the emerging themes of the importance of rapport and empathy, the presentation of self and the role of emotions are, and how they inform the students' awareness of (im)politeness norms.

\section{Discussion and conclusions}

In this chapter I explored reflective writing texts produced by medical students at an English university with an interpersonal pragmatics lens. Despite the fact that the course in which these texts were written does not teach pragmatics or issues of (im)politeness explicitly on a meta-level, the focus on communication skills nevertheless allows students to address and learn about pragmatic issues

11 The student also write about positive encounters and thus do not exclusively report on problematic experiences. 
that are pertinent to norms of behaviour in their community of practice. The discussion of the texts shows that concerns about (im)politeness arise naturally during this reflection process on relational work. Lexemes such as rude or patronizing, etc. are used in the texts as metapragmatic comments on relational work that ultimately designate speakers' assessments as to whether they have treated others appropriately or whether they have been treated themselves according to their expectations of the appropriate norms of the interaction in question. The texts also reveal that the students feel insecure about the very norms of the doctor-patient interaction, in which they find themselves for the first time in the role of doctors rather than patients.

The choice of topics reveals that the students do not perceive doctor-patient interactions to be focused only on the transactional side of communication. They choose to report most on rapport and empathy among the clinical communication skills discussed, and make their own and their patients' emotions a topic in its own right. They thus reflect that, as future doctors, they will not only be confronted with the biomedical side of their profession, but they will also have to learn to become good communicators and to handle the considerable emotional strain that their profession entails.

The role of emotions has long been recognized as an important aspect of a doctor's profession. The students are both encouraged to use empathy and to create rapport (see, e.g., Maguire and Pitceathly 2002) but are also warned about the possibility of 'compassion fatigue' which might lead to burn-out (see, e.g., Pfifferling and Gilley 2000). Drawing on Hochschild's (1979, 1983) work, Erickson and Grove (2008: 707) reveal that there are conflicting norms at play: "we generally expect that our doctors and nurses approach our health care with a certain level of empathic concern," and on the other hand, "emotional detachment, neutrality, and/or emotional control" are taught as "fundamental to providing quality care and to preserving their own health and well-being." Some of the examples above described exactly this dilemma with which the students are confronted from the very beginning so that the importance of making 'emotional labor' (Erickson and Grove 2008; Hochschild 1979, 1983) an explicit teaching object is confirmed by the texts in the corpus (Locher and Koenig 2014).

Next to and intertwined with the role of emotions and the use of empathy and the creation of rapport, the students also discussed the presentation of self. The data revealed rich emic understandings of relational processes and their connection to identity construction. The students reflect on the difficulty of striking a balance between appearing professional and appearing genuinely involved (just as pointed out by Erickson and Grove above) and on avoiding the appearance of being patronizing or rude. It is argued that these real-life 
examples are more pertinent than any text-book example to develop understanding of interpersonal pragmatic processes.

To conclude from this case study, reflective writing tasks can be considered a good first step to make people aware of their subconscious expectations about their roles and their behaviour in different communities of practice. By writing about an encounter that they experienced themselves, the writers are put into the position of experts, which empowers them. The issues that emerge can then be discussed with a supervisor or in class, depending on the context in which the task is performed. Becoming aware of one's discourse system, of the assumptions about rights and obligations that pertain to roles that we take for granted in daily lives, is argued to be the first step in learning about relational work and (im)politeness. Learning about (im)politeness is thus not a task that we can tick off after having managed to acquire the grammar system of our first language, nor does it only apply in intercultural contexts in which a second language is involved. Instead the process of learning about (im)politeness is closely intertwined with social interaction in different contexts. Each individual is constantly challenged throughout their lifetime to adapt to new situations and to engage in relational work which serves the interpersonal and transactional goals of the encounter in question.

\section{Acknowledgments}

My sincere thanks go to Swiss National Science Foundation $(126959,144541)$ for funding the early research phases of this project ('Life (beyond) Writing': Illness Narratives, 2009-2012) and to all the Nottingham medical students and their teacher Victoria Tischler, who have allowed the research team to use their texts for this study. I also thank Victoria Tischler and Regula Koenig for their constructive feedback on this chapter. In addition, I express my sincere thanks to the project member Regula Koenig (responsible for supervising the topic and theme analysis) and the interns who helped us with data analysis at various stages of the project: Ellen Brugger, Olga Brühlmann, Florence Bühler, Evelyne Iyer-Grüniger, Dino Kuckovic, Nathalie Meyer, Ruth Partl, and Andrea Wüst. Andrea Wüst also gave valuable input on the qualitative analysis in section 4.3. Finally, I thank Barbara Pizziconi and the anonymous reviewers for their constructive criticism. 


\section{References}

Agha, Asif. 2007. Language and social relations. Cambridge: Cambridge University Press.

Béal, Christine. 1994. Keeping the peace: A cross-cultural comparison of questions and requests in Australian English and French. Multilingua 13(1-2). 35-58.

Brady, Donald W., Giselle Corbie-Smith \& William T. Branch, Jr. 2002. "What's important to you?": The use of narratives to promote self-reflection and to understand the experiences of medical residents. Annals of Internal Medicine 137(3). 220-223.

Branch, William T., Jr. \& Anuradha Paranjape. 2002. Feedback and reflection: Teaching methods for clinical settings. Academic Medicine 77(12). 1185-1188.

Brown, Penelope \& Stephen C. Levinson. 1978. Universals in language usage: Politeness phenomena. In Esther Goody (ed.), Questions and politeness: Strategies in social interaction (Cambridge Papers in Social Anthropology 8), 56-289. Cambridge: Cambridge University Press.

Brown, Penelope \& Stephen C. Levinson. 1987 [1978]. Politeness. Some universals in language usage (Studies in Interactional Sociolinguistics 4). Cambridge: Cambridge University Press.

Bucholtz, Mary \& Kira Hall. 2005. Identity and interaction: A sociocultural linguistic approach. Discourse Studies 7(4-5). 585-614.

Culpeper, Jonathan. 2008. Reflections on impoliteness, relational work and power. In Derek Bousfield \& Miriam A. Locher (eds.), Impoliteness in language. Studies on its interplay with power in theory and practice (Language, Power and Social Process 21), 17-44. Berlin \& New York: Mouton de Gruyter.

Culpeper, Jonathan. 2011. Impoliteness: Using language to cause offence. Cambridge: Cambridge University Press.

Eckert, Penelope \& Sally McConnell-Ginet. 1992. Communities of practice: Where language, gender, and power all live. In Kira Hall, Mary Bucholtz \& Birch Moonwomon (eds.), Locating power. Proceedings of the second Berkeley women and language conference, 89-99. Berkeley, CA: Berkeley Women and Language Group.

Erickson, Rebecca J. \& Wendy J. C. Grove. 2008. Emotional labor and health care. Sociology Compass 2(2). 704-733.

García-Pastor, María Dolores. 2012. EFL teaching with a view to the classroom. In María Dolores García-Pastor (ed.), Teaching English as a foreign language: Proposals for the language classroom (Estratègies 6), 11-26. Valencia: Perifèric.

Gibbs, Graham. 1988. Learning by doing: A guide to teaching and learning methods. London: Further Education Unit.

Grice, H. Paul. 1975. Logic and conversation. In Peter Cole \& Jerry L. Morgan (eds.), Syntax and semantics, volume 3: Speech acts, 41-58. New York: Academic Press.

Gumperz, John J. \& Celia Roberts. 1978. Developing awareness skills for interethnic communication. Middlesex: National Centre for Industrial Language Training.

Gygax, Franziska, Regula Koenig \& Miriam A. Locher. 2012. Moving across disciplines and genres: Reading identity in illness narratives and reflective writing texts. In Rukhsana Ahmed \& Benjamin R. Bates (eds.), Medical communication in clinical contexts: Research and applications, 17-35. Dubuque, IA: Kendall Hunt.

Gygax, Franziska, Regula Koenig, Miriam A. Locher \& Victoria Tischler. 2013. Interdisziplinäres Forschungsprojekt: «Life (Beyond) Writing: Illness Narratives». Bulletin SAGW [Schweizerische Akademie der Geistes- und Sozialwissenschaften] 3. 60-61. 
Halpern, Jodi. 2003. What is clinical empathy? Journal of General Internal Medicine 18(8). 670-674.

Hampton, Martin. 2010a. Reflective writing: A basic introduction. http://www.port.ac.uk/media/ contacts-and-departments/student-support-services/ask/downloads/Reflective-writinga-basic-introduction.pdf (3 February 2014).

Hampton, Martin. 2010b. Basic essay structure. http://www.port.ac.uk/media/contacts-anddepartments/student-support-services/ask/downloads/Basic-essay-structure.pdf (3 February 2014).

Haugh, Michael, Dániel Z. Kádár \& Sara Mills. 2013. Interpersonal pragmatics: Issues and debates. Journal of Pragmatics 58. 1-11.

Hochschild, Arlie Russell. 1979. Emotion work, feeling rules, and social structure. American Journal of Sociology 85(3). 551-575.

Hochschild, Arlie Russell. 1983. The managed heart: Commercialization of human feeling. Berkeley, CA: University of California Press.

Kádár, Dániel Z. \& Michael Haugh. 2013. Understanding politeness. Cambridge \& New York: Cambridge University Press.

Lakoff, Robin Tolmach. 1973. The logic of politeness, or minding your p's and q's. Chicago Linguistics Society 9. 292-305.

Langlotz, Andreas \& Miriam A. Locher. 2012. Ways of communicating emotional stance in online disagreements. Journal of Pragmatics 44(12). 1591-1606.

Langlotz, Andreas \& Miriam A. Locher. 2013. The role of emotions in relational work. Journal of Pragmatics 58. 87-107.

Leech, Geoffrey. 1983. Principles of pragmatics. New York: Longman.

Levinson, Stephen C. 1992. Activity types and language. In Paul Drew \& John Heritage (eds.), Talk at work: Interaction in institutional settings (Studies in Interactional Sociolinguistics 8), 66-100. Cambridge: Cambridge University Press.

Lo, Adrienne \& Kathryn M. Howard. 2009. Mobilizing respect and politeness in classrooms. Linguistics and Education 20(3). 211-216.

Locher, Miriam A. 2008. Relational work, politeness, and identity construction. In Gerd Antos \& Elja Ventola in cooperation with Tilo Weber (eds.), Handbook of interpersonal communication (Handbooks of Applied Linguistics 2), 509-540. Berlin: Mouton de Gruyter.

Locher, Miriam A. 2012. Politeness research from past to future, with a special focus on the discursive approach. In Lucía Fernández-Amaya, Maria de la 0 Hernández López, Reyes Gómez Morón, Manuel Padilla Cruz, Manuel Mejias Borrero \& Mariana Relinque Barranca (eds.), New perspectives on (im)politeness and interpersonal communication, 36-60. Newcastle: Cambridge Scholars.

Locher, Miriam A. 2013. Politeness. In Carol E. Chapelle (ed.), The Encyclopedia of Applied Linguistics, n.p. Malden, MA: Wiley-Blackwell.

Locher, Miriam A. \& Sage L. Graham. 2010. Introduction to interpersonal pragmatics. In Miriam A. Locher \& Sage L. Graham (eds.), Interpersonal pragmatics (Handbooks of Pragmatics 6), 1-13. Berlin: Mouton de Gruyter.

Locher, Miriam A. \& Regula Koenig. 2014. 'All I could do was hand her another tissue' Handling emotions as a challenge in reflective writing texts by medical students. In Andreas Langlotz \& Agnieszka Soltysik Monnet (eds.), Emotion, affect, sentiment: The language and aesthetics of feeling (Swiss Papers in English Language and Literatue 30), 121-141. Tübingen: Narr. 
Locher, Miriam A., Regula Koenig \& Janine Meier. 2015. A genre analysis of reflective writing texts by English medical students: What role does narrative play? In Franziska Gygax \& Miriam A. Locher (eds.), Narrative matters in medical contexts across disciplines (Studies in Narrative 20), 141-164. Amsterdam: John Benjamins.

Locher, Miriam A. \& Andreas Langlotz. 2008. Relational work: At the intersection of cognition, interaction and emotion. Bulletin Suisse de Linguistique Appliquée 88. 165-191.

Locher, Miriam A. \& Richard J. Watts. 2005. Politeness theory and relational work. Journal of Politeness Research 1(1). 9-33.

Locher, Miriam A. \& Richard J. Watts. 2008. Relational work and impoliteness: Negotiating norms of linguistic behavior. In Derek Bousfield \& Miriam A. Locher (eds.), Impoliteness in language. Studies on its interplay with power in theory and practice (Language, Power and Social Process 21), 77-99. Berlin \& New York: Mouton de Gruyter.

MacQueen, Kathleen M., Eleanor Mclellan-Lemal, Kelly Bartholow \& Bobby Milstein. 2008. Team-based codebook development: Structure, process, and agreement. In Greg Guest \& Kathleen M. MacQueen (eds.), Handbook for team-based qualitative research, 119-136. Lanham: Altamira Press.

Maguire, Peter \& Carolyn Pitceathly. 2002. Key communication skills and how to acquire them. British Medical Journal 325. 697-700.

Mann, Karen, Jill Gordon \& Anna MacLeod. 2009. Reflection and reflective practice in health professions education: A systematic review. Advances in Health Science Education 14(4). 595-621.

Namey, Emily, Greg Guest, Lucy Thairu \& Laura Johnson. 2008. Data reduction techniques for large qualitative data sets. In Greg Guest \& Kathleen M. MacQueen (eds.), Handbook for team-based qualitative research, 137-162. Lanham: Altamira Press.

Monash University. 2012. What is reflective writing? http://www.monash.edu.au/lls/llonline/ writing/medicine/reflective/1.xml (28 September 2014).

Ochs, Elinor. 1988. Culture and language development: Language acquisition and language socialization in a Samoan village (Studies in the Social and Cultural Foundations of Language 6). Cambridge: Cambridge University Press.

Ochs, Elinor. 1999. Socialization. Journal of Linguistic Anthropology 9(1-2). 203-233.

Oyebode, Femi \& Victoria Tischler. 2015. Applying narrative to medical education: Medicine and storytelling. In Franziska Gygax \& Miriam A. Locher (eds.), Narrative matters in medical contexts across disciplines (Studies in Narrative 20), 183-205. Amsterdam: John Benjamins.

Pizziconi, Barbara. 2009. Stereotyping communicative style in and out of the language and culture classroom: Japanese indirectness, ambiguity and vagueness. In Reyes Gómez Morón, Manuel Padilla Cruz, Lucía Fernández Amaya \& María de la 0 Hernández López (eds.), Pragmatics applied to language teaching and learning, 221-254. Newcastle: Cambridge Scholars.

Pfifferling, John H. \& Kay Gilley. 2000. Overcoming compassion fatigue. Family Practice Management 7(4). 39-44.

Rose, Kenneth R. 2000. An exploratory cross-sectional study of interlanguage pragmatic development. Studies in Second Language Acquisition 22(1). 27-67.

Scollon, Ron \& Suzanne Wong Scollon. 1990. Athabaskan-English interethnic communication. In Donal C. Carbaugh (ed.), Cultural communication and interactional contact, 261-290. Hilldsdale, NJ: Lawrence Erlbaum.

Scollon, Ron \& Suzanne Wong Scollon. 2001. Intercultural communication: A discourse approach 2nd edn. Oxford: Blackwell. 
Scollon, Ron, Suzanne Wong Scollon \& Rodney H. Jones. 2012. Intercultural communication: $A$ discourse approach 3rd edn. Oxford: Blackwell.

Shapiro, Johanna, Deborah Kasman \& Audrey Shafer. 2006. Words and wards: A model of reflective writing and its uses in medical education. Journal of Medical Humanities 27(4). 231-244.

Spencer-Oatey, Helen. 2007. Theories of identity and the analysis of face. Journal of Pragmatics 39(4). 639-656.

Spencer-Oatey, Helen. 2011. Conceptualising 'the relational' in pragmatics: Insights from metapragmatic emotion and (im)politeness comments. Journal of Pragmatics 43(14). 3565-3578.

Tannen, Deborah. 1993. What's in a frame?: Surface evidence for underlying expectations. In Deborah Tannen (ed.), Framing in discourse, 14-56. Oxford: Oxford University Press.

Thomas, Jenny. 1983. Cross-cultural pragmatic failure. Applied Linguistics 4(2). 91-112.

Watton, Pete, Jane Collings \& Jenny Moon. 2001. Reflective writing: Guidance notes for students. http://www.exeter.ac.uk/fch/work-experience/reflective-writing-guidance.pdf (28 September 2014).

Wenger, Etienne. 1998. Communities of practice: Learning, meaning, and identity. Cambridge: Cambridge University Press. 
Brought to you by | Universitaetsbibliothek Basel

Authenticated Download Date | 5/1/17 10:33 AM 